\title{
DESVIACIÓN DEL CURSO CAUSAL E IMPRUDENCIA INCONSCIENTE
}

\author{
Mario Sánchez Dafauce \\ Profesor Visitante de Derecho Penal. \\ Universidad Carlos III de Madrid.
}

\begin{abstract}
SUMARIO: I. Tipo objetivo e imprudencia inconsciente. II. La imputación al dolo. III. La realización del riesgo en el resultado en caso de comportamiento alternativo conforme a Derecho. IV. Conclusiones.
\end{abstract}

Resumen: En el presente trabajo se estudian diversos problemas del tipo penal: las consecuencias sistemáticas de la ausencia de tipo subjetivo en la imprudencia inconsciente, la diferencia entre imputación objetiva e imputación al dolo en las desviaciones del curso causal y la realización del riesgo en resultado en caso de comportamiento alternativo conforme a Derecho.

Palabras clave: Tipo imprudente, dolo eventual, error en el golpe, previsibilidad, realización del riesgo en el resultado, comportamiento alternativo conforme a Derecho.

Abstract: In the present paper we discuss the systematic consequences of the absence of mens rea in the unconscious negligence, the difference between dolus eventualis and negligence in the deviations of the causal course, and the realization of the risk in the result in cases of alternative behavior according to Law.

Keywords: Negligence, dolus eventualis, aberratio ictus, foreseeability, realization of the risk in the result, alternative behavior according to Law. 


\section{Tipo objetivo e imprudencia inconsciente}

Una de las muchas y relevantes aportaciones del profesor Roxin a la dogmática penal es el nuevo impulso dado a la teoría de la imputación objetiva. Es muy difícil imaginar hoy un desarrollo de los problemas que plantea el tipo penal sin la utilización como instrumento de trabajo de la imputación objetiva. Esta teoría da un perfil más definido a problemas ya conocidos y trabajados, como la causalidad adecuada o la volición en el dolo, y abre la puerta a un nuevo modelo teórico, cuyo resultado final aún no se conoce, en materias como la infracción de la norma de cuidado o las relaciones entre tipo objetivo y tipo subjetivo. También es concebible un uso extensivo de criterios de imputación para el logro de una mejor comprensión de problemas tan diversos como la presencia de los presupuestos de hecho de una causa de justificación, el contenido material del dominio del hecho, los presupuestos teóricos de la víctimo-dogmática, o incluso la propia categoría dogmática de la culpabilidad.

En concreto, el giro dado al estudio de la imprudencia resulta sumamente significativo. En la cuarta edición del primer tomo de su Parte General, mantiene Roxin su ya conocida conclusión de que la imprudencia inconsciente es desnuda imputación objetiva, con lo que carece de tipo subjetivo $^{1}$. Esta afirmación, como se sabe, abre un campo amplísimo de posibilidades teóricas. Veamos algunas de ellas.

1. Un primer problema nacido directamente de la presencia de tipos penales sin tipicidad subjetiva es el de las relaciones sistemáticas entre imprudencia y dolo. El tipo subjetivo, en principio, presupone la materia de la tipicidad (de la infracción, si se acepta un dolo de injusto). Esta materia es el principal objeto de trabajo de la teoría de la imputación objetiva. Ahora bien, si la imprudencia inconsciente, como afirma Roxin, es ya, y nada más, un tipo objetivo perfecto, la aparición del dolo no puede modificar el carácter imprudente del hecho objetivo. En otros términos, la imprudencia inconsciente se convierte en objeto de referencia del dolo. Esto es muy significativo porque, en primer lugar, se desdibuja la atribución al dolo de una mayor capacidad de realización del resultado resuelta en sede de tipicidad subjetiva y, en segundo lugar, porque, al quedar la imprudencia consciente en el tipo subjetivo, se hace posible que un tipo

\footnotetext{
1 Así, en la imprudencia inconsciente falta el tipo subjetivo porque precisamente el sujeto no ha incluido en su representación los elementos y presupuestos del tipo objetivo, Roxin, Strafrecht. Allgemeiner Teil. Band I. Grundlagen. Der Aufbau der Verbrechenslehre, 4. Auflage, C.H. Beck, München, 2006, 24/74, p. 1090; también, Derecho Penal. Parte General. Tomo I. Fundamentos. La estructura de la teoría el delito, traducción de la 2. ${ }^{\text {a }}$ edición alemana (1994) por Luzón PeÑa, Díaz y García Conlledo, y De Vicente Remesal, Civitas, Madrid, 1997, 24/67, p. 1022.
} 
objetivo de imprudencia inconsciente se convierta en un tipo subjetivo de imprudencia consciente. Trataré ambas cuestiones por separado.

A. La pertinencia de una imputación objetiva aun en el tipo doloso procede del hecho de que no todo lo que se desea y se consigue es penalmente relevante. Una vez satisfechas las exigencias de manejo de elementos subjetivos en sede de tipicidad objetiva (sobre lo que volveré más adelante), el dolo aporta el conocimiento del objeto, pero no modifica tal objeto, que consiste fundamentalmente en la creación de un riesgo relevante de lesión.

Esta independencia del objeto es aceptada implícitamente por diversas instituciones. Así, por ejemplo, la imprudencia inconsciente entendida como el incumplimiento de una exigencia de control. O la imprudencia inconsciente grave si tal gravedad se hace depender de criterios alcanzados en sede de tipicidad objetiva, normalmente el mayor o menor grado de probabilidad de lesión. También es interesante comprobar cómo, incluso para los defensores de un factor volitivo más o menos cargado en los casos de dolo eventual, la diferencia entre dolo eventual e imprudencia consciente, en supuestos de alto grado de probabilidad de lesión, ya ha sido resuelta en el tipo objetivo, pues, se dice, la confianza insensata del autor en un buen final casi imposible ha de ser penalmente irrelevante ${ }^{2}$. En estos casos, el dolo no aporta un mayor desvalor derivado del mayor grado de probabilidad de lesión que otorga la dirección causal; al contrario, el grado de probabilidad de lesión es un presupuesto del dolo.

Son conocidos casos en los que una imprudencia es grave por la razón de que se puede saber (ex ante) que la realización de la conducta va a provocar el resultado lesivo con una probabilidad rayana en la certeza. Son casos, por decirlo así, en los que, si hubiera aparecido la consciencia (y si tal aparición no hubiese servido para evitar el hecho), lo habría hecho bajo la forma de dolo directo. Este dolo directo, además, no habría aportado nada a un hecho objetivo cuya probabilidad ex ante de lesión ya rozaba sin él el cien por cien; si bien, junto a estos casos, son imaginables otros en los que el tipo doloso es el producto de una previa imputación objetiva en la que, a su vez, y dada la relevancia del riesgo, el grado

2 Véase, al respecto, Luzón PeÑa, quien considera que, pese a que el dolo eventual requiere de un elemento volitivo en forma de aceptación o consentimiento, se puede restringir lo que se considera aceptación o no aceptación por medio de una valoración objetivo-normativa, de tal modo que la confianza irracional e infundada en la no producción del hecho (una confianza meramente subjetiva que no es más que un deseo jurídicamente irrelevante) ha de mantener vivo el factor volitivo del dolo, pues objetivamente, es decir, desde el punto de vista jurídico y del hombre medio ideal, no es posible confiar con algo de base en que no se realice el hecho: Luzón Peña, Lecciones de Derecho Penal. Parte Gene-

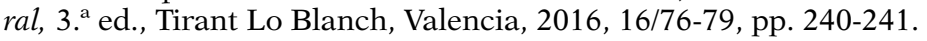


de probabilidad de lesión es menor. De tal modo que puede decirse que el dolo, por el hecho de conocer y querer el resultado, habitualmente se va a asociar con grados altos de probabilidad de lesión, si bien el hecho de conocer y querer no es en ocasiones ni siquiera constitutivo de dolo, pues tal conocimiento y voluntad no se proyectan sobre un riesgo relevante de lesión.

La asociación entre mayor desvalor del tipo doloso y mayor grado de probabilidad de lesión no explica la pena superior que en todo caso le corresponde al tipo doloso respecto del imprudente, con independencia del grado de probabilidad de lesión alcanzado gracias al dolo, que puede ser muy inferior (dentro de la creación de un riesgo relevante) al grado de probabilidad de lesión de una simple imprudencia inconsciente. No explica, tampoco, por qué, cuando no está incriminado el tipo imprudente, este mayor grado de probabilidad de lesión es atípico, siendo típico otro menor (dado el dolo). Y, por último, tampoco explica por qué se prevé la misma pena para todos los tipos dolosos, aunque encierren un muy diferente grado de probabilidad de lesión, con tal de que satisfagan las exigencias del juicio de imputación objetiva. La coherencia teórica obligaría en estos casos a incluir la mayor o menor probabilidad de lesión abarcada por el dolo entre los criterios para la determinación de la pena, pues sería un elemento más del conjunto designado como gravedad del hecho.

Se puede dar respuesta a todas estas preguntas si se estima que el mayor desvalor que revela la siempre mayor, y a veces única, pena para el tipo doloso procede del hecho de que el dolo no solo provoca una lesión del bien jurídico, sino, a su vez, una lesión del valor social de dicho bien jurídico. Un homicidio imprudente lesiona el bien jurídico «vida humana independiente». Un homicidio doloso, sin ánimo de precisión técnica, lesiona el bien jurídico "vida humana independiente» $\mathrm{y}$ atenta contra el «valor social de la vida humana independiente». El homicidio imprudente mata, el homicidio doloso mata y devalúa la vida; todo lo cual no es sino una nueva variación sobre el clásico valor ético-social de la acción, que Welzel colocó en el centro mismo de su teoría del delito y sin el cual resulta difícil hallar una explicación completa del significado penal del dolo. No hay que olvidar, por otro lado, que Roxin, tras la etapa histórica de enfrentamiento entre causalismo y finalismo, hace de la relevancia social del dolo el fundamento de su ubicación en el tipo penal ${ }^{3}$.

Por otro lado, es también importante despojar el concepto de dolo de todo lo que no sea conocimiento (y, en su caso, voluntad) de los elementos del tipo objetivo (y ello con independencia de la necesidad de elaborar un concepto normativo de imputación al dolo para la solución

3 «Si se atribuye al tipo la misión de tipificar el contenido de merecimiento de pena del correspondiente delito (...), no se puede renunciar al dolo para perfilar el tipo delictivo", $P G$, (tr. . $^{\text {a }}$ ), 1997, 10/63, p. 308; AT I, 4. Auflage, 2006, 10/63, p. 310. 
de problemas específicos, como la tipicidad subjetiva de las desviaciones causales). Es cierto que el dolo ha de ser tratado como un objeto independiente de valoración, pero también lo es que solo es posible construir el dolo como tal objeto independiente de valoración si se le otorga un contenido material a su objeto propio de referencia, es decir, a la tipicidad objetiva ${ }^{4}$. Un avance en esta dirección se puede dar si algunos de los problemas relacionados con el grado de riesgo que habitualmente son tratados en el tipo subjetivo pasan a convertirse en problemas de tipicidad objetiva. Gráficamente se diría que la separación de diferentes niveles de riesgo objetivo predeterminaría la distinción entre dolo e imprudencia consciente. Si se desea que la idea de dolo encierre un concepto técnico cuya definición incluya unos elementos mínimos comunes, lo que haya de diferenciar a sus diferentes formas de aparición ha de proceder de su objeto de referencia: en el dolo directo, el conocimiento y la voluntad de un resultado (casi) seguro; en el dolo eventual, el conocimiento y la voluntad de un resultado probable. Más tarde se abordará el componente volitivo del dolo.

De acuerdo con lo anterior, la diferencia entre dolo eventual e imprudencia consciente se comprende mejor si, llevando a sus últimas consecuencias la teoría de la representación, queda convertida en un problema de tipicidad objetiva y, por lo tanto, de grado de riesgo. Son conocidas, no obstante, las críticas al empleo de los criterios de posibilidad y probabilidad de lesión. En este sentido se han manifestado autores como, por ejemplo, Roxin o Hassemer, quien llega a comparar su uso con el intento de que un flan permanezca clavado en la pared ${ }^{5}$.

${ }^{4}$ Frisch estima que en muchos requisitos añadidos a la causalidad y acentuados subjetivamente, si se observan las cosas con más detenimiento, enseguida «se llega a la conclusión de que estos requisitos subjetivos poseen siempre un núcleo objetivo y que lo objetivo se intenta incluir, de algún modo en lo subjetivo». Y aunque conceptos globales como la "creación de un peligro desaprobado" no satisfagan todas las exigencias de concreción, «describen al menos el baremo fundamental y están abiertos a admitir ulteriores criterios más precisos que decidan sobre la desaprobación de la creación del peligro», Frisch, "La imputación objetiva: estado de la cuestión», Sobre el estado de la teoría del delito. (Seminario en la Universitat Pompeu Fabra), Civitas, Madrid, 2000, pp. 53 y 55; traducción de Ricardo Robles Planas.

$5 \mathrm{Si}$, «como tradicionalmente se hace en ámbitos cognitivos», se discute «sobre la alternativa posibilidad vs. probabilidad, se refuerzan de nuevo los problemas respecto a la utilización práctica de estas teorías. Por un lado, los criterios "posible" y "probable" contienen sólo una fuerza cuantificadora y, por consiguiente, no permiten ninguna diferenciación cualitativa entre dolo e imprudencia (...). Por otro lado, los criterios "posible" y "probable" en lo referente al peligro externo, carecen de precisión ¿dónde termina exactamente la posibilidad y dónde empieza la probabilidad? ¿Qué grados —y cómo se determinan - de posibilidad y probabilidad son suficientes? Si se pretende construir la representación vaga e incierta que de la situación externa tiene el juzgador sobre la base de la representación que tenía el sujeto en el momento de actuar - como exige una imputación a título de dolo- el intento está destinado a tener tanto éxito como que un flan permanezca clavado en la pared», Hassemer, «Los elementos característicos del dolo», Persona, mundo y responsabilidad. Bases para una teoría de la imputación en Derecho Penal, Tirant 
La crítica que en esta misma dirección hace Roxin de un dolo cognitivo, basado en un pronóstico puramente intelectual de probabilidad, sobre cuyos grados pocos sujetos reflexionan ${ }^{6}$, no resulta convincente, al menos en alguien que ha hecho de la relevancia del riesgo el criterio central para la solución de los problemas de imputación objetiva. Así como la definición de un límite de relevancia del riesgo (un criterio esencialmente cuantitativo) permite diferenciar la imprudencia inconsciente del caso fortuito, la definición de un límite de probabilidad de lesión serviría para diferenciar la imprudencia consciente del dolo eventual. No se puede realizar una crítica de la distinción cuantitativa entre probabilidad y mera posibilidad de lesión, y aceptar sin más una diferenciación también cuantitativa entre relevancia e irrelevancia del riesgo de lesión ${ }^{7}$. La frontera entre relevancia e irrelevancia es tan delicada como la diferencia entre probabilidad y posibilidad. Pero ambas son necesarias para una correcta comprensión de la tipicidad objetiva. La razón por la que la segunda, a diferencia de la primera, no ha pasado finalmente la prueba de la aceptación científica radica en el hecho de que en los casos fronterizos entre imprudencia consciente y dolo eventual, dado un posible pero no seguro riesgo de lesión, el contenido del dolo como enfrentamiento con el orden jurídico se desdibuja, lo que lleva a buscar el fundamento de la

lo Blanch, Valencia, 1999, pp. 142-143, n. 64; traducción de M. ${ }^{a}$ DEL Mar DíAz Pita. Hassemer pone aquí de manifiesto las insuficiencias de todo criterio objetivo basado en la división según niveles de riesgo. Ahora bien, las preguntas que plantea son perfectamente extensibles a la relevancia del riesgo en relación con el juicio de imputación objetiva. Para la crítica a un concepto cognitivo de dolo eventual, véase RoXIN, $A T$, $4 .^{\mathrm{a}}, 2006,12 / 41-52$, pp. 455-459. La contemplación de la diferencia entre dolo e imprudencia consciente como un problema del tipo objetivo es propia de Herzberg, para quien el dolo no tiene que ver con el hecho de que el autor haya tomado en serio un peligro conocido, sino con el hecho de que haya conocido un peligro serio, «Die Abgrenzung von Vorsatz und bewusster Fahrlässigkeit -ein Problem des objektiven Tatbestandes», Juristische Schulung (JuS), 1986, Heft 4, p. 262. Una crítica a Herzberg puede verse también en Roxin, $A T$, 4. ${ }^{\text {, }}$, 2006, 12/6569 , pp. $465-467$.

6 Roxin, $A T, 4 .^{\mathrm{a}}, 2006,12 / 46$, p. 457.

7 La relevancia del riesgo, ampliamente aceptada por la doctrina como criterio de imputación objetiva, tiene uno de sus principales puntos de partida en el fundamental artículo de Roxin Reflexiones sobre la problemática de la imputación en Derecho penal. En él podemos leer que en «la esfera de los delitos imprudentes el criterio de la previsibilidad objetiva sirve para impedir la imputación de lesiones de bienes jurídicos que se han producido accidentalmente en los casos de conductas que no comportan un riesgo jurídicamente relevante de producción de un resultado; y no otra cosa sucede con los delitos dolosos pese toda la variedad de fundamentaciones que se han buscado: nadie apreciará una acción de homicidio porque la recomendación de un viaje en avión dé lugar a que por estrellarse el aparato muera, conforme se deseaba, el tío a quien se quiere heredar. Ahora bien, quien niegue que aquí exista dolo, tendría que reconocer que no se ha creado en absoluto un riesgo jurídicamente relevante y que, por ello, objetivamente ya no era posible la imputación del resultado. La falta de dolo es entonces un fenómeno secundario», «Reflexiones sobre la problemática de la imputación en Derecho penal», Problemas básicos del Derecho penal, Reus, Madrid, 1976, p. 132; traducción de Diego-Manuel Luzón PeÑa (original de 1970). 
punición dolosa en diversos e inconcretos elementos volitivos. Pero esta pérdida de claridad de los contornos de un concepto es propia de todos los casos en los que la separación entre el sí y el no se hace depender de cantidades, dependencia de la que el Derecho penal no puede prescindir (relevancia o irrelevancia del riesgo, realización de ese riesgo - y no de otro- en el resultado, restricciones ético-sociales a la legítima defensa, mal mayor o mal menor en el estado de necesidad, o minoría de edad penal).

Por lo expuesto, la confianza del sujeto en la no realización de un resultado lesivo solo puede ser manejada por el Derecho penal si se traduce en un control del curso causal. La mera confianza no es más que un peculiar conocimiento especial, pues hay algo que el sujeto sabe: que prefiere que no se realice el resultado a pesar del aparente grado de riesgo de lesión. Dado que la sociedad siempre se va poner en el nivel de conocimiento de quien posee el conocimiento especial, al autor que no desea un resultado ha de exigírsele que haga uso de tal conocimiento para evitar el hecho lesivo o disminuir el riesgo de lesión. Si no lo hace, dada la relevancia del riesgo, realizará un determinado tipo objetivo, y si conoce todos los elementos de ese tipo objetivo, habrá actuado con dolo ${ }^{8}$. Por otro lado, quien busca un resultado con más fuerza de la que le permiten las circunstancias, en tanto no genera un riesgo relevante de lesión, vive de su deseo, como bien demuestra la teoría de la imputación objetiva. Esta teoría es necesaria porque, a pesar de una hipotética voluntad de realización del resultado, existe una diferencia, ajena a dicha voluntad, entre caso fortuito e imprudencia. Lo mismo puede decirse de la diferencia entre imprudencia consciente y dolo eventual. El elemento que permite realizar esta distinción, como en el caso de la imputación objetiva, es el grado de riesgo de lesión.

B. La afirmación de que la imprudencia inconsciente carece de tipo subjetivo no solo influye en la relación entre imputación objetiva y dolo, sino que también modifica las relaciones entre imprudencia inconsciente e imprudencia consciente. Es evidente que si la imprudencia consciente se resuelve en sede de tipicidad subjetiva, la respuesta a la pregunta que en sede de tipicidad objetiva se ha formulado en relación con la imprudencia inconsciente aún no otorga una calificación definitiva del correspondiente tipo imprudente. Para sortear esta dificultad, es necesario afirmar que todo tipo objetivo de lesión es una imprudencia incons-

8 Armin Kaufmann estima que la confianza en la evitación del resultado solo excluye el dolo si por la forma de selección de los medios y de la dirección se hace patente en el curso de la acción misma. Con ello se alcanza una "objetivación del límite del dolo», «El dolo eventual en la estructura del delito. Las repercusiones de la teoría de la acción y de la teoría de la culpabilidad sobre los límites del dolo", Anuario de Derecho penal y Ciencias Penales (ADPCP), 1960, pp. 198-199; traducción de Suárez Montes. 
ciente. Esta imprudencia inconsciente de todo tipo doloso o imprudente consciente es insoslayable, pues es precisamente el objeto de referencia tanto del dolo como de la consciencia de la imprudencia consciente ${ }^{9}$. No obstante, con ello no quedan plenamente explicadas las relaciones entre imprudencia consciente e imprudencia inconsciente.

La voluntad típica es el resultado de la suma de conocimiento y conducta; no es una simple expresión de deseos. Esto es así porque lo que al Derecho penal le importa no es el hecho subjetivo como expresión de un sentido posible, sino como expresión de un sentido dado, que puede denominarse "plan normativo del autor objetivado». Por ello, la aparición de la consciencia en el tipo subjetivo, aunque vaya acompañada de una intensa voluntad de realización, no motiva la aparición automática del dolo. La irrelevancia del riesgo asigna el resultado al azar. La relevancia del riesgo asigna el resultado a la acción. A su vez, la probabilidad de lesión asigna el resultado al autor como portador de un sentido, mientras que la posibilidad de lesión, desde el nivel mínimo de relevancia hasta el límite con la probabilidad, asigna el resultado al autor como portador de un riesgo. Esta distinción es político-criminalmente correcta, pues una imprudencia inconsciente menos grave, fronteriza con la ausencia de imputación objetiva, no debe convertirse en un tipo doloso si aparecen el conocimiento y la voluntad de realización; conclusión apenas controvertida, pues incluso los seguidores de las teorías volitivas del dolo eventual introducen criterios de corrección y recorte del campo de acción de la desnuda voluntad ${ }^{10}$.

Ahora bien, las consecuencias sistemáticas de esta opinión general no han sido deducidas ni siquiera por los partidarios de la teoría de la representación. Si hay una barrera objetiva que el dolo - y su desvalor - no pueden atravesar, y si esa barrera está ya dentro de la tipicidad objetiva, la conclusión necesaria es que hay más de un tipo objetivo de resultado. Lo más sencillo será afirmar que existen dos tipos objetivos propios de la denominada imprudencia inconsciente: el que corresponde a la imprudencia inconsciente menos grave y el que corresponde a la imprudencia inconsciente grave. Con ello se está diciendo que la imputación objetiva

9 Con esto no se quiere decir que el «no hecho» de la imprudencia inconsciente se convierta en un «hecho» merced a una posterior representación del riesgo en el tipo subjetivo, sino que la imprudencia inconsciente, sin esa representación posterior, es solo un hecho objetivo y, en consecuencia, un «no hecho» subjetivo. (Agradezco esta advertencia, así como sus demás consideraciones, al evaluador de este trabajo).

${ }_{10}$ La atención al grado de probabilidad de lesión como factor, no único, pero sí central, de la distinción entre dolo eventual e imprudencia consciente es manifiesta en la siguiente afirmación de Roxin: «El riesgo [de transmisión del virus $\mathrm{VIH}$ ] en caso de relación sexual sin protección está, según el conocimiento médico actual, entre el $0,1 \%$ y el $1 \%$.». Tal riesgo, "si no concurren circunstancias especiales que eleven el peligro, se mueve evidentemente en una dimensión que habla decididamente en contra del dolo eventual», Roxin, $P G$, (tr. $2{ }^{a}$ ), 1997, 12/72, nota 136, pp. 452-453; AT I, 4. Auflage, 2006, 12/83, nota 169 , p. 476. 
no solo satisface las exigencias de definición de la relevancia penal mínima de un riesgo, sino que prepara el camino para una diferente tipicidad global del hecho en caso de que se confirme la consciencia del autor. Uno de los elementos (por supuesto, no el único) de esta diferente tipicidad global del hecho será el grado de riesgo de lesión.

Lo que sí es cierto, no obstante, es que, si el grado de riesgo se convierte en un elemento del tipo objetivo, el desconocimiento del grado de probabilidad de lesión del tipo objetivo podrá conducir al error de tipo. Esto puede hacer pensar en un momento volitivo que corrija la representación equivocada del autor, si bien cabe otra alternativa: una vez objetivada la consciencia de realización del tipo utilizando como límites de la representación correcta los límites internos de cada uno de los tipos objetivos, se niega el error si no se desconoce ningún factor de riesgo, es decir, si solo hay una diferente evaluación —no basada en un conocimiento especial- del riesgo.

Como resumen de lo expuesto puede decirse que existen dos tipos objetivos de lesión, la imprudencia grave y la imprudencia menos grave. El primero, dada la consciencia del autor, lleva al tipo subjetivo de la imprudencia consciente. El segundo, dada la consciencia del autor, lleva al tipo subjetivo del dolo. Solo son necesarios dos diferentes tipos objetivos, pues en sede de tipicidad subjetiva solo es relevante la diferencia entre posibilidad y probabilidad de lesión. Si se estimase necesaria políticocriminalmente una diferencia de trato entre dolo eventual y dolo directo, el tipo objetivo - afirmada la imputación objetiva- debería dividirse en tres subtipos, de modo que quedase preparada también la diferencia entre probabilidad y cuasicerteza de lesión. El esquema de las relaciones sistemáticas entre imprudencia y dolo es el siguiente:

Tipos objetivos:

1. Imprudencia grave (probabilidad o certeza de lesión).

2. Imprudencia menos grave (posibilidad de lesión).

3. Ausencia de imputación objetiva (irrelevancia del riesgo de lesión): ausencia de tipo objetivo.

Tipos subjetivos:

1a) Conocimiento: dolo; 1b) Desconocimiento (ausencia de tipo subjetivo): mantenimiento, en su caso, del tipo (objetivo) 1 .

2a) Conocimiento: imprudencia consciente; 2b) Desconocimiento (ausencia de tipo subjetivo): mantenimiento, en su caso, del tipo (objetivo) 2 .

Deseo hacer, en relación con este apartado, tres últimas aclaraciones. En primer lugar, la imputación objetiva ha quedado reducida al problema de la creación de un riesgo relevante, pues la ausencia de realización 
del riesgo (relevante) en el resultado plantea un problema específico propio de la tentativa, con lo que lo dicho puede servir para la distinción entre punibilidad de la tentativa con dolo eventual e impunidad de la imprudencia consciente sin resultado. En segundo lugar, la relevancia del riesgo ha sido admitida como criterio rector del juicio de imputación objetiva, pues con ella salta a la vista la necesidad de un baremo de ponderación del grado de riesgo que perfile los contornos del tipo objetivo. Como la pretensión de este trabajo es la utilización de dicho baremo para la solución de diversos problemas típicos, he desatendido la mención de otros criterios necesarios que completan la imprudencia y la imputación objetiva como instituciones jurídicas ${ }^{11}$. Por último, el tipo subjetivo ha sido entendido como conocimiento de los elementos del tipo objetivo, lo cual no obsta a que el núcleo valorativo del dolo se siga depositando en la voluntad de realización del tipo objetivo ${ }^{12}$. Se acepta, por lo tanto, que hay un conocimiento, el propio de la imprudencia consciente, del que no se puede deducir la voluntad de realización del tipo, si bien esta voluntad, presupuesto el conocimiento, se hace depender exclusivamente del grado de probabilidad de lesión afirmado en el tipo objetivo ${ }^{13}$.

11 En particular, no se aborda en este trabajo la controvertida relación entre imputación objetiva e infracción de la norma de cuidado; solo se pretende trasladar la probabilidad de lesión, en el sentido de la teoría de la representación, del dolo eventual al tipo objetivo. Véase, sobre tipo objetivo y contrariedad al deber, RoBles PlanAs: «si la esencia del injusto imprudente está en la realización de una conducta contraria al deber de cuidado, y en esa medida, desaprobada, difícilmente puede afirmarse que quien obra en error (de tipo) invencible obra también, desde un punto de vista "objetivo", de forma desaprobada», "La "teoría de la imputación objetiva": algunas consideraciones sobre sus orígenes y futuro", Estudio preliminar en Frisch: La imputación objetiva del resultado. Desarrollo, fundamentos y cuestiones abiertas, Atelier, Barcelona, 2015, p. 39.

${ }_{12} \mathrm{La}$ imprudencia consciente queda como imprudencia (objetiva) menos grave. Si el mero conocimiento de la posibilidad de lesión debe estimarse como un factor que agrava la imprudencia, lo cual aquí ni se discute ni se admite, ello será un problema propio del tipo subjetivo.

13 Schünemann construye un concepto tipológico de dolo que incluye tanto «un elemento subjetivo», «la motivación psicológica individual del autor», como "las circunstancias de la situación», y, con ello, «un momento objetivo que marca asimismo la máxima de acción y del cual el autor no se puede distanciar cuando lo ha incorporado a su consciencia». En este sentido, «si el elemento de la capacidad de dirección o el elemento del ánimo de indiferencia hacia el bien jurídico se encuentran conformados de la forma más sólida, basta para cumplimentar el concepto de dolo que el otro elemento presente una expresión mínima. De este modo, el concepto de dolo también engloba las acciones intencionales en las que las probabilidades de producción del resultado son muy pequeñas, al igual que si se tratara de acciones con dolo directo en relación con consecuencias accesorias de algún modo queridas. Por lo demás, tratándose de acciones llevadas a cabo conociendo la mera posibilidad lesiva, es necesario que se den otros momentos de disvalor, para que así el elemento del ánimo se encuentre presente», ScHüNEMANN, «De un concepto filológico a un concepto tipológico de dolo», Temas actuales y permanentes del Derecho penal después del milenio, Tecnos, Madrid, 2002, pp. 105-108; traducción de MAriana Sacher y Carlos Suárez González. Para Herzberg, véase, junto al texto ya citado, «Das Wollen beim Vorsatzdelikt und dessen Unterscheidung vom bewusst fahrlässigen Verhalten», Juristenzeitung (JZ), 1988, pp. 573 y ss. La tesis de Schünemann ha de poner- 
2. Un segundo problema provocado por la existencia de tipos completos objetivos es el de la aceptación de que hay hechos penalmente relevantes sin tipo subjetivo, lo que implica que se puede acceder al contenido global de desvalor de un injusto penal prescindiendo de la tipicidad subjetiva. El principal problema que plantea esta afirmación es el del reconocimiento del título de imputación de un hecho a un sujeto que, podríamos decir, no está presente en el momento del hecho. Así, se puede defender que la imprudencia inconsciente deje de ser manejada como un problema penal precisamente porque la ausencia de hecho subjetivo ha de poner en pie todas las garantías propias del Derecho penal del hecho, en especial el principio de culpabilidad y la vocación preventiva de la pena. No obstante, no suele negarse la evidencia de que la imprudencia inconsciente es un importante problema social, con lo que pasa a un primer plano el papel preventivo-general desempeñado por la pena en estos casos. Dado que, como se acepta mayoritariamente, la culpabilidad penal es una culpabilidad por el hecho, y dado que la pena es la consecuencia jurídica de la culpabilidad, la amenaza de pena, como apelación racional al autor para que evite su conducta, necesita de un autor presente en el momento del hecho. Esto, en la imprudencia inconsciente, solo se consigue ampliando el hecho hacia atrás en el tiempo. Pero, a su vez, tal expediente, fuera de una hipotética actio libera in causa, acoge rasgos de la culpabilidad por el carácter.

Dado que pueden realizarse inconscientemente conductas imprudentes con resultados gravísimos, parece que la orientación político-criminal correcta es la que hace de la imprudencia inconsciente un asunto propio del Derecho penal. Ahora bien, la consecuencia obligada de tal calificación es la exclusiva legitimación preventivo-especial de la pena. Esto significa que la consecuencia jurídico-penal asociada a la imprudencia inconsciente debería hallarse más cerca de la medida de seguridad que de la pena. En la actualidad, de hecho, la pena para el autor de una imprudencia inconsciente encierra una remisión a la propia conciencia; remisión impuesta a alguien que no pretende poner en cuestión el orden jurídico-penal, pero hecha con el deseo de que modifique su forma de obrar. Junto con el aislamiento del peligro, la razón por la que la inter-

\footnotetext{
se en relación con su opinión — diferente de la de Roxin — de que «en el delito doloso, el riesgo permitido debe ser determinado al menos de un modo considerablemente más restringido en los casos en que el autor actúa con el propósito de lesionar», pues es posible que "los criterios de imputación sean diferentes en el delito doloso con respecto a los del delito culposo, a saber, más exigentes», "Consideraciones sobre la teoría de la imputación objetiva», Temas actuales y permanentes del Derecho penal después del milenio, Tecnos, Madrid, 2002, p. 86; traducción de MARIANA SACHER. La propuesta que hago en el presente trabajo resuelve este problema de otro modo: en niveles bajos de relevancia del riesgo, la consciencia (incluso tan cargada afectivamente como pueda estarlo un dolo directo de primer grado) da como resultado la imprudencia consciente. Con ello pretendo caminar dentro de la identidad mantenida por Roxin entre las reglas de imputación del tipo doloso y las del tipo imprudente.
} 
vención, en los casos más graves, y a salvo los factores retributivos, se concentra en la pérdida de la libertad deambulatoria es clara: puesto que la persona no quiere infringir, la mejor reeducación es la reflexión ${ }^{14}$. Esto es correcto, pues la pena solo puede enseñar a ser prudente, pero no, como regla general, a serlo en cada sector específico de la actividad humana ${ }^{15}$.

\section{La imputación al dolo}

1. Un tercer grupo de problemas cuya solución depende directamente de las relaciones sistemáticas que se propongan entre tipo objetivo y tipo subjetivo es el de la imputación al dolo en las desviaciones causales. El ejemplo perfecto de esto lo proporciona la institución de la aberratio ictus, pues en ella las soluciones teóricas van desde el extremo de la realización del plan interno del autor, hasta el contrario de la ausencia de un campo propio para la imputación al dolo una vez satisfecho el juicio de imputación objetiva. Se puede decir que estas dos soluciones extremas pecan al no querer incurrir cada una en el error de la otra, con lo que ambas tienen parte de razón ${ }^{16}$.

La realización del plan del autor como criterio para la imputación al dolo en las desviaciones causales, y, por lo tanto, como criterio para la solución de problemas de tipicidad subjetiva, desarrollado y utilizado por Roxin ${ }^{17}$, permite una clara y didáctica separación de los problemas de desviación del curso causal que afectan a la realización del riesgo en

14 Francisco Tomás y Valiente indica que ya las Partidas conocían las diferencias entre homicidio doloso, fortuito o culposo: «en el primero se impone la pena ordinaria, la pena de homicida propiamente dicha; en el "homicidio por ocasión", "non se cae por ende en pena ninguna"; en el culposo, se indica como pena la de "destierro en alguna ysla por cinco años"», El Derecho penal de la monarquía absoluta (siglos XVI, XVII y XVIII), 2. ${ }^{a}$ ed., Tecnos, Madrid, 1992, pp. 305-306.

${ }_{15}$ Con un alcance general, alude GómEz-BENítez a una crisis del fundamento teórico del sistema dualista. Esta crisis «se ha agudizado extraordinariamente cuando se ha reconocido que las penas y las medidas de seguridad coinciden en su función protectora de bienes jurídicos y, además, se unifica el fin de ambos instrumentos en la prevención especial». Así, la introducción de «un tejido de garantías en el ámbito reservado a las medidas de seguridad postdelictuales pone de manifiesto que la culpabilidad no es el único principio garantístico, sino que también las propias exigencias preventivas pueden limitarse atendiendo a elementales principios de racionalidad político-criminal», «Sobre lo interno y lo externo, lo individual y lo colectivo en el concepto penal de culpabilidad», Política criminal y nuevo Derecho penal. Libro Homenaje a Claus Roxin, SiLva Sánchez (Ed.), Bosch, Barcelona, 1997, p. 275.

16 Sobre la relación entre dolo e imputación objetiva, véase ANARTE Borrallo, Causalidad e imputación objetiva. Estructura, relaciones y perspectivas, Servicio de Publicaciones de la Universidad de Huelva, 2002, pp. 342-353.

17 Roxin, $P G$, (tr..$^{\mathrm{a}}{ }^{\mathrm{a}}$ ), 1997, 12/135-176, pp. 486-508; AT I, 4. Auflage, 2006, 12/151201, pp. 509-535. 
el resultado de los que afectan al dolo. Pero esta clara distinción sistemática se consigue a cambio de una proyección del dolo sobre un objeto de referencia mucho mayor que la tipicidad objetiva. El dolo no es el resultado de la imputación de elementos ya manejados en sede de tipicidad objetiva, sino que nace con un contenido nuevo, más amplio. Esto sirve para parapetar su frontera con la imputación objetiva, pero difumina los contornos de sus límites subjetivos. Así, por ejemplo, el plan del autor que desea organizar un tumulto para disolver una manifestación y dispara para ello desde larga distancia a un manifestante cualquiera ${ }^{18}$, puede no realizarse tanto porque la bala ha alcanzado a su hijo como porque la bala ha alcanzado a un conductor de autobús. Es posible que, por ejemplo, su deseo de disolución de la manifestación se subordine al deseo de que su hijo continúe con vida, pero también es posible que lo haga al deseo de que no muera ningún conductor de autobús, pues para eso puede tener las razones que quiera. Pese a la distinción que hace Roxin entre "realización del plan del hecho según un juicio objetivo» y "según el criterio del propio sujeto» ${ }^{19}$, lo que importa observar es el hecho de que, dado que ni la condición de hijo ni la condición de conductor de autobús son elementos objetivos del tipo de homicidio, el criterio de control de la realización del plan del autor - que es el criterio de verificación del dolo- no puede extraerse en ningún caso del tipo objetivo. Si no se desea que estos casos queden a gusto del intérprete, el criterio de la realización del plan del autor se debe hacer depender de un referente de verificación que incluya las exigencias político-criminales que se consideren adecuadas, pero que de ningún modo serán las propias del tipo objetivo, que ha sido sobrepasado. El dolo queda así convertido en algo más que conocimiento y voluntad del tipo objetivo, y en algo más que en una imputación de la voluntad de realización del tipo objetivo. El dolo se convierte en la realización de un plan extratípico mediante la realización de un tipo objetivo.

2. La solución exactamente contraria a la anterior es la defendida por quienes, como Gómez Benítez, concluyen que la afirmación de la imputación objetiva agota todo el proceso de imputación. Dada la imputación objetiva, no hay margen para la imputación al dolo ${ }^{20}$. Para Gómez-Benítez, «es ineludible incluir en el tipo objetivo (como objeto del dolo, por tanto) cierto nivel de determinación del curso causal. El curso causal, es decir, la forma de producirse el resultado, no es totalmente irrelevante para el tipo objetivo, ya que es expresión concreta del peligro para el bien jurídico que el autor se representa al poner en práctica su plan (dolo),

18 Roxin, $P G$, (tr. 2. $\left.{ }^{a}\right), 1997,12 / 150$, pp. 494-495; AT I, 4. Auflage, 2006, 12/166, p. 518.

19 Roxin, $P G$, (tr. 2. ${ }^{\text {a }), ~ 1997, ~ 12 / 150, ~ p p . ~ 494-495 ; ~ A T ~ I, ~ 4 . ~ A u f l a g e, ~ 2006, ~ 12 / 166, ~ p . ~} 518$.

20 Véase, como crítica general a la institución de la imputación objetiva en el delito doloso, Armin Kaufmann, "¿ “Atribución objetiva" en el delito doloso?», Anuario de Derecho penal y Ciencias Penales (ADPCP), 1985, pp. 807 y ss.; traducción de JoAQuín CuELlo. 
y que tiene que realizarse en el resultado (desviación inesencial). Ese nivel normativo de determinación del curso causal es el que delimita, precisamente, la previsibilidad según el plan del autor: todo curso causal previsible según el plan del autor pertenece al tipo objetivo, y es, en consecuencia, objeto del dolo; el conocimiento exigible al autor, al respecto, para la imputación dolosa se deduce de la propia previsibilidad según su plan, que per se permite afirmar, al menos, el nivel de conocimiento del dolo eventual» ${ }^{21}$.

El problema central que plantea el texto de Gómez Benítez es el siguiente: ¿ es correcta una imputación independiente al dolo una vez aceptado el carácter inesencial de una desviación causal o, por el contrario, la aceptación de la previsibilidad del resultado en sede de tipicidad objetiva es ya una afirmación implícita del dolo eventual respecto de ese resultado efectivamente producido? La respuesta a la que llega el autor, minoritaria en la doctrina, es la de que el juicio de previsibilidad -el núcleo del criterio de realización del riesgo en el resultado- proporciona ya una imputación al dolo sin necesidad de un criterio añadido en sede de tipicidad subjetiva, y sin que, por lo tanto, sea correcta una diferenciación técnica en este ámbito de problemas entre el tipo imprudente y el tipo doloso.

Los argumentos proporcionados por el autor para negar la posibilidad de este doble nivel de imputación son los siguientes:

a) Los criterios de imputación objetiva «remiten el objeto de referencia del factor cognoscitivo del dolo al peligro objetivo (desaprobado) de que acontezca el resultado concreto como consecuencia de la acción, es decir, al conocimiento de la probabilidad objetiva del resultado (previsibilidad)» ${ }^{22}$. Por lo tanto, y puesto que no existe dolo típico de lo inadecuado o imprevisible, quienes admiten en la doctrina este doble nivel de imputación objetiva e imputación al dolo, «tienen la carga de probar que puede haber existido previsibilidad y previsión del resultado, sin que exista, no obstante, dolo, o más concretamente, que pese a ello, no concurre la parte cognoscitiva del dolo en relación a ese resultado típico» ${ }^{23}$. «Desde

${ }^{21}$ Gómez Benítez, «La realización del peligro en el resultado y la imputación al dolo en las desviaciones causales», Estudios penales, COLEX, Madrid, 2001, pp. 143-144. Publicado en: Omisión e imputación objetiva en Derecho penal. Jornadas hispano-alemanas de Derecho Penal en homenaje al profesor Claus Roxin, Gimbernat, Schünemann, Wolter, (Edits.), Centro de Estudios Judiciales, Servicio de Publicaciones de la Facultad de Derecho de la Universidad Complutense, Madrid, 1994. También publicado en: los mismos, Internationale Dogmatik der objektiven Zurechnung und der Unterlassungsdelikte, C.F. MüLLER, HEIDELBERG, pp. 25 y ss.

${ }^{22}$ Gómez BeNítez, «La realización del peligro en el resultado y la imputación al dolo en las desviaciones causales», Estudios penales, 2001, p. 142.

${ }_{23}$ Gómez Benítez, «La realización del peligro en el resultado y la imputación al dolo en las desviaciones causales», Estudios penales, 2001, pp. 138-139. 
la teoría de la imputación objetiva, no parece (...) tan importante resaltar su autonomía y prioridad sistemáticas respecto al dolo, como la trascendencia que el factor cognoscitivo del dolo tiene para la imputación al tipo objetivo, así como la que el tipo objetivo así construido tiene para el propio concepto de dolo típico» ${ }^{24}$.

Gómez Benítez entra con estas reflexiones en el complejo campo de las relaciones entre imprudencia y dolo, y proporciona una conclusión sistemática de alto valor, como es la necesaria estructura imprudente de todo tipo doloso, es decir, la consideración de la imprudencia como presupuesto necesario y no solo como alternativa del dolo. Con ello se abre el camino hacia la consideración de los diferentes grados del dolo como diferentes grados de probabilidad objetiva de lesión. Además, con la influencia mutua entre dolo típico e imputación objetiva se avanza hacia un concepto normativo de dolo, es decir, hacia la creación de criterios objetivos de imputación en sede de tipicidad subjetiva.

b) El criterio utilizado por Roxin para la imputación al dolo es el plan del autor. Gómez Benítez rechaza que, tras el empleo de un factor cognoscitivo en sede de imputación objetiva, se pueda mantener un ámbito normativo diferente para la imputación al dolo. Si el plan del autor es ya un elemento necesario del juicio de previsibilidad objetiva, lo que forma parte de él para la realización del riesgo en el resultado no puede ser coherentemente excluido después en la construcción del dolo. En opinión de Gómez Benítez, este punto débil de la teoría de la imputación objetiva conduce a una absorción automática del tipo imprudente por el tipo doloso en los casos de desviación no esencial del curso causal: no hay un segundo criterio cognoscitivo de referencia que fundamente la posibilidad de un doble criterio de imputación. Así, «la previsibilidad del curso causal se define teniendo en cuenta lo que pertenece al plan del autor, porque no puede negarse el dolo eventual de lo que es previsible según el plan» ${ }^{25}$.

Con esta crítica, queda señalada, en mi opinión, la dirección necesaria para mantener un ámbito independiente de imputación al dolo en las desviaciones no esenciales del curso causal: la construcción de un contexto cognoscitivo de la imprudencia diferente del propio del dolo y, con ello, la creación de una normatividad de la imprudencia (el deber de cuidado) diferente de la normatividad del dolo, para que de tal modo puedan darse resultados previsibles que no formen parte del plan del autor.

${ }^{24}$ Gómez Benítez, «La realización del peligro en el resultado y la imputación al dolo en las desviaciones causales», Estudios penales, 2001, p. 139.

${ }_{25}$ Gómez Benítez, «La realización del peligro en el resultado y la imputación al dolo en las desviaciones causales», Estudios penales, 2001, p. 143. 
c) Por último, Gómez Benítez critica el criterio del cambio de valoración jurídica como forma de solución de los casos de aberratio ictus. La imputación objetiva y la imputación al dolo no deben ser sustituidas por el criterio de la valoración distinta del hecho, «ya que lo decisivo no es dicha valoración, sino si el cambio de valoración debido a una desviación del golpe es imprevisible, o no, según el plan del autor». Si es previsible (presupuesto necesario de la aparición de un problema de imputación al dolo), «da lugar a un curso causal adecuado y, por tanto, a la imputación objetiva del resultado y a su simultánea imputación al dolo (eventual), como sucede en toda desviación causal que se considera inesencial ${ }^{26}$. Por lo tanto, el criterio del cambio de valoración jurídica, dado que ya está abarcado por el juicio de previsibilidad, y dado que es un problema de previsibilidad objetiva el que incorrectamente se desea resolver solo con él, es un criterio técnicamente inútil y debe rechazarse.

La tesis de Gómez Benítez cuenta ciertamente con diferentes argumentos a su favor. Ya veíamos que la imprudencia puede aparecer tanto en el tipo objetivo como en el tipo subjetivo. También es conocida la incidencia de determinados elementos subjetivos en el juicio de imputación objetiva ${ }^{27}$. Y, por supuesto, no hay que desatender la idea de que el tipo objetivo es el contenido material y el objeto de referencia del dolo. Ahora bien, toda esta movilidad de elementos típicos no nos puede hacer perder de vista que el tipo penal de resultado se construye en dos niveles, uno fundamentalmente objetivo, cuyo núcleo es la imputación objetiva, y uno principalmente subjetivo, cuyo centro es el dolo. Si, por muy complejo que sea, no se consigue en los casos de desviación del curso causal un nivel de imputación al dolo diferente del propio de la imputación objetiva, la afirmación de la imprudencia implicará automáticamente la afirmación del dolo. Y ello es una solución político-criminal-

26 Gómez BEnítez, «La realización del peligro en el resultado y la imputación al dolo en las desviaciones causales», Estudios penales, 2001, pp. 145-146.

${ }_{27}$ Señala acertadamente Cancio Meliá que «si de lo que se trata es de una determinación general de los límites de la tipicidad objetiva en el sentido de general, no puede ser decisivo que los datos introducidos en este juicio sean, desde un punto de vista externo-natural, de naturaleza "objetiva" o "subjetiva". Al igual que otros datos del contexto que permiten esa valoración objetiva en el sentido de general, un dato subjetivo como el conocimiento de determinado hecho puede incluirse en el tipo objetivo sin que se destruyan las barreras entre tipo objetivo y subjetivo: pues la valoración en la que es introducida ese dato es distinta de la que procede realizar en el tipo subjetivo». Y el significado «intersubjetivo» de la conducta "puede variar en función de los datos conocidos por el sujeto actuante», "Algunas reflexiones sobre lo objetivo y lo subjetivo en la teoría de la imputación objetiva», Estudios de Derecho Penal, 2010, Palestra, Lima, pp. 150-151. 
mente discutible, pues amplía excesivamente los límites de la incriminación dolosa ${ }^{28}$.

3. En tercer lugar, la idea de cambio de la valoración jurídica, como posible vía intermedia entre las dos mencionadas, aporta una solución satisfactoria a un buen número de casos, pero lo hace por aproximación, pues su contenido teórico es sencillamente tautológico, dado que, en cada caso, el cambio de valoración jurídica solo excluye el dolo cuando no ha sido abarcado por el dolo, y la teoría nace porque el cambio de valoración jurídica no suele ser abarcado por el dolo. Por último, y en cuanto a las teorías de la concreción y la equivalencia, Gómez Benítez advierte que «no parece correcto que en las desviaciones causales dentro del marco de lo previsible (inesenciales) se afirme que el sujeto conoce el hecho (dolo) y, en cambio, en las desviaciones del golpe sin cambio de tipicidad e igualmente previsibles, no» ${ }^{29}$. No obstante, la teoría de la equivalencia puede ser satisfactoria como regla general en los casos de error en la persona o en el objeto, pues es habitual que en ellos la persona u objeto particulares no sean elementos del tipo, de modo que no se produce un error en relación con la creación de un riesgo relevante, algo que sí puede ocurrir en los casos de aberratio ictus.

4. Ninguno de los modelos de solución mencionados satisface la necesidad que subyace a la elaboración de un criterio de imputación al dolo en las desviaciones causales. El modelo de Roxin porque rompe la relación entre tipo objetivo y tipo subjetivo; el modelo de Gómez Benítez porque la distinción en tales casos entre tipo doloso y tipo imprudente es una exigencia político-criminal, pero también porque, en tanto en nuestro Derecho cabe la imputación objetiva (con la consiguiente realización del riesgo en el resultado) en caso de imprudencia inconsciente, hay que afirmar que cabe la imputación objetiva sin consciencia alguna del riesgo, de modo que la previsibilidad no implica necesariamente tal consciencia; y el modelo del cambio de valoración jurídica porque, al desconocer el fundamento de la selección, elige como factor definitorio uno frecuente.

La creación de un escalón de imputación al dolo diferente del satisfecho en sede de tipicidad objetiva solo es posible si se encuentra un modo particular de completar un aparente déficit cognitivo del autor, pues el dolo, entendido como voluntad de realización del tipo objetivo, si bien no

${ }_{28}$ Como señala acertadamente Silva Sánchez, no ha de entenderse que «dada una conducta dolosamente realizada, el que acaezca un resultado cualquiera, para cuya producción esa conducta era adecuada ex ante, determine el cumplimiento del tipo del delito doloso consumado», "Aberratio ictus" e imputación objetiva», Anuario de Derecho penal y Ciencias Penales (ADPCP), 1984, p. 367.

29 Gómez Benítez, «La realización del peligro en el resultado y la imputación al dolo en las desviaciones causales», Madrid, 2001, pp. 145-146. 
es necesariamente el producto del conocimiento del tipo objetivo (caso de la imprudencia consciente), solo puede aparecer como producto de tal conocimiento.

La idea de una imputación al dolo nos habla de un conocimiento a primera vista inexistente que, si se observa mejor, aparece. Ahora bien, como ese conocimiento ha de presumir el tipo objetivo, debe diferenciarse necesariamente del deber de conocer, es decir, ha de ser un conocimiento que: a) presuponga el deber de conocer (pues ha de dejar atrás la imprudencia); b) no exista en una primera aproximación (pues ha de ser imputado); y c) se pueda afirmar (pues tal imputación ha de hacerse al dolo). Con tales exigencias, no puede sino observarse con interés la solución escéptica de Gómez Benítez.

No obstante, este independiente juicio de imputación puede imaginarse si se construye una distinta verdad material. La verdad del tipo objetivo, más prolija en detalles, es la verdad de la persona promedio (previsibilidad objetiva), que se sirve del conocimiento del autor - también del conocimiento superior, con lo que coloca a toda la sociedad a esa altura- para emitir un juicio de riesgo. La imputación al dolo, más selectiva, atiende a la verdad de quien, metido en la cabeza del autor, elabora la lista de todo lo que por ese autor es conocido pese a no ser advertido (previsibilidad subjetiva). La primera toma en consideración las circunstancias del caso, la situación general que sirve de escenario a la conducta del autor. La segunda - en la que, pese a estudiarse un problema de tipicidad subjetiva, hace falta una persona promedio, como en todo proceso de imputación - toma en consideración solamente lo que el autor se representa, y deduce de ahí lo que debe entenderse conocido como consecuencia necesaria de dicha representación ${ }^{30}$.

Con ello es evidente que no se elude la afirmación, realizada por Gómez Benítez, relativa al hecho de que el dolo se convierte en previsibilidad $^{31}$.

${ }^{30}$ Contra la identificación de dolo y voluntad en el dolo directo de segundo grado y en el dolo eventual, véase GIMBERNAT ORDEIG, «Acerca del dolo eventual», Estudios de Derecho penal, 3. a edición, Tecnos, Madrid, 1990 , pp. 254-260. Para la previsibilidad como criterio jurídico, véase GImBERnat ORdeIG, Cursos causales irregulares e imputación objetiva, B de F, Montevideo-Buenos Aires, 2011, pp. 109-113.

31 Así, pese a que no existe «dolo típico de lo inadecuado/imprevisible», "prescindir de la exigencia de que el factor cognoscitivo del dolo esté actualizado en el momento del hecho" conduce a una confusión entre previsibilidad y efectiva previsión, para evitar lo cual «hay que explicar el resultado como realización del peligro implícito en el plan del autor. En este sentido, la previsibilidad del curso causal se define teniendo en cuenta lo que pertenece al plan del autor, porque no puede negarse el dolo eventual de lo que es previsible según su plan», GómEZ BENítez, «La realización del peligro en el resultado y la imputación al dolo en las desviaciones causales», Madrid, 2001, pp. 142-143. En otro sentido, Silva SÁnchez estima que una conducta puede contener en sí varios riesgos determinables ex ante. "Para dar lugar a la responsabilidad por delito doloso consumado es preciso que el resultado sea realización de uno de los riesgos abarcados por el dolo 
Pero sí se contesta convenientemente a la aserción de que la verificación del juicio de previsibilidad en sede de imputación objetiva impide la concreción de un criterio más restrictivo para la imputación al dolo en casos de ausencia de previsión efectiva del curso causal. En ambos juicios, el resultado es, digamos, un hecho psíquico potencial, pero el hecho potencial de la tipicidad objetiva alude a una capacidad obtenida utilizando como criterio de referencia un ámbito de conocimiento más amplio. En la tipicidad subjetiva, en la que la propia idea de una imputación al dolo impide una remisión directa a la efectiva previsión del autor, solo se pretende que el hecho potencial sea un producto necesariamente unido a la representación del sujeto. Se trataría de una definición normativa del dolo apoyada exclusivamente en el grado de probabilidad de realización de cursos causales íntimamente unidos al efectivamente previsto ${ }^{32}$.

del sujeto y no de otro no creado dolosamente por éste. Aunque sea un riesgo presente en su conducta y determinable ex ante en ésta». Se consideran riesgos distintos los que amenazan a bienes jurídicos de diferente clase o naturaleza (ej., vida y propiedad), los que amenazan a bienes jurídicos distintos aunque de la misma clase o naturaleza (ej., las diferentes vidas reales, empíricas, protegidas en el tipo de homicidio), y aquellos en cuya formación o configuración contribuyen factores diferentes, que permiten hablar de diversas clases de riesgo aunque todos afecten al mismo bien jurídico, "Aberratio ictus" e imputación objetiva», $A D P C P, 1984$, pp. 369-374. Para MIR PUIG, la solución a los casos de aberratio ictus «depende del concepto de bien jurídico que se maneje. Si por bien jurídico se entiende un valor abstracto (así, "la" vida, "la" salud, etc. como valores abstractos), será coherente la solución de estimar irrelevante el error y admitir un delito doloso consumado: porque se quería lesionar ese valor y se ha conseguido, aunque sobre un objeto material distinto. Pero si, como parece más correcto, se entiende por bien jurídico un objeto empírico dotado de ciertas característica típicas que lo hacen valioso, no será relevante el error sobre características no típicas como la identidad de la víctima a la que se dirige el ataque, a sabiendas de que la misma reúne las condiciones típicas (...), pero sí el error sobre la dirección del ataque al objeto empírico», pues, si se alcanza otro objeto empírico equivalente y cercano al atacado, «la agresión dolosa no se habra dirigido a este bien jurídico", Derecho Penal. Parte General, 10. a edición, Ed. Reppertor, Barcelona, 2016, 10/138, pp. 285-286. Sobre error y desviación del curso causal, véase, también, Luzón Peña, Lecciones de Derecho Penal. Parte General, 3. ${ }^{a}$ ed., Tirant Lo Blanch, Valencia, 2016, 17/34-48, pp. 256-261. Este autor advierte que se trata de "casos especiales de error de tipo porque el error sobre uno de sus elementos se añade a una conducta inicial dolosa del sujeto, lo que no sucede en el error de tipo normal», Lecciones de Derecho Penal. Parte General, 3. a , 2016, p. 256. Esta particularidad ha podido influir en la apreciación de Gómez Benítez de que no cabe disgregar previsibilidad y dolo respecto del resultado efectivo.

32 Una definición cognitiva del dolo apoyada en la "co-consciencia» puede verse en Gimbernat Ordeig, «Acerca del dolo eventual», Estudios de Derecho penal, 3. ${ }^{\text {a }}$, 1990, pp. 254-260. Un completo estudio sobre el dolo y su determinación es el realizado por RAGUÉS I VALLÈS, para quien el dolo ha de extraerse del sentido social de un hecho y de las circunstancias que lo acompañan, existiendo una serie de conocimientos mínimos atribuibles a toda persona normalmente socializada, El dolo y su prueba en el proceso penal, Bosch, Barcelona, 1999, pp. 323 y ss. Para Puppe, solo se puede construir «una diferencia entre la representación del autor acerca del curso causal y el curso causal real que excluya el dolo pero fundamente la imprudencia, cuando se exigen a la representación del autor sobre el curso causal y a la probabilidad de producción del resultado unos requisitos más elevados en los casos de dolo que en los de imprudencia. Entonces cabe que las repre- 
Así, por ejemplo, si alguien dispara desde una azotea con la intención de matar a un determinado personaje público, realiza un homicidio doloso si, sin ni siquiera haberse imaginado tal cosa, mata a uno de los numerosos y visibles guardaespaldas que lo rodean, y ello pese a que dicha muerte no impida, como era su propósito, la celebración de un posterior mitin electoral. Por el contrario, si se pasea por primera vez por la línea de tiro una persona a la que el autor unas horas antes, y sin saber bien qué es lo que hacía, ha dado permiso para moverse por la azotea, y lo hace con la mala suerte de ser alcanzada mortalmente por el disparo, nos hallaremos ante un homicidio imprudente, y ello a pesar de que dicha muerte, que no hay que olvidar que satisface las exigencias de la tipicidad objetiva para los casos de desviación del curso causal, por cualquier ironía del destino conduzca a la cancelación del mencionado mitin electoral.

Por supuesto, y en coherencia con lo dicho en la primera parte de este trabajo, el dolo requerirá de un determinado grado de probabilidad de lesión ofrecido ya por el tipo objetivo. De no llegar hasta él, y siempre que tal insuficiencia no impida la afirmación de la creación de un riesgo relevante, el debate planteado, en principio intrascendente en cuanto a la desviación del curso causal, lo será entre imprudencia consciente e imprudencia inconsciente. No obstante, esto no obliga a la elaboración de un momento volitivo como criterio para la imputación al dolo. En el ejemplo anterior, si quien ha obtenido el permiso del autor del disparo para pasearse inocentemente por un lugar que se halla en la línea de tiro, sin percatarse de ello el autor, y habiendo olvidado este último tal permiso, ha cruzado ya esa línea de tiro en múltiples ocasiones en los momentos inmediatamente anteriores al disparo, el tipo objetivo será el

sentaciones de autor sólo coincidan con el curso causal real en tantos elementos como es necesario para fundamentar el reproche de imprudencia, pero no en tantos como es necesario para fundamentar el dolo». Para dar respuesta a la necesidad que existe «de vincular la imputación a título de dolo a requisitos más estrictos que los que rigen en materia de imprudencia», es preciso anclar esta distinción en un determinado concepto de dolo, entendido como un "juicio adscriptivo» en caso de que el autor obre con conocimiento de un peligro de producción del resultado si «un hombre razonable a su lado» no hubiera llevado a cabo tal acción «sin contar, aprobándolo, con el resultado y conformándose con su producción», y ello con independencia del debate interno del autor sobre las consecuencias de su acción. Además de constituir un método idóneo de causación del resultado, tal peligro «debe estar gráficamente ante los ojos del autor», Puppe, «La imputación del resultado al dolo», Estudios de Derecho penal. Homenaje al profesor Santiago Mir Puig, Silva Sánchez, Queralt Jiménez, Corcoy Bidasolo, Castiñeira Palou (Coords.), B de F, Montevideo-Buenos Aires, 2017, pp. 807-809.; traducción de Jesús-María Silva Sánchez. Cercano a la "co-consciencia» se encuentra también el TS cuando afirma que, para calificar correctamente los casos de aberratio ictus, «se debe tener en cuenta si el segundo objeto sobre el que recayó y sufrió la lesión estaba o no a la vista del autor. Si ciertamente estaba a su vista, se debe admitir el llamado dolo alternativo cuando el desarrollo causal no era improbable» (STS 148/2002, de 7 de febrero); también STS 647/2009, de 12 de junio, y STS 1230/2006, de 1 de diciembre, donde se especifica que la víctima que falleció estaba «indudablemente (...) abarcada por la vista del autor». 
propio de una imprudencia inconsciente grave, pues el grado objetivo de riesgo de realización del resultado habrá sobrepasado la frontera de la probabilidad, pero no habrá imputación al dolo ni tipo subjetivo doloso, pues al no conocer el autor los paseos de la víctima, estos no pueden ser incluidos en los elementos del juicio intersubjetivo del dolo potencial (sí en el juicio objetivo de riesgo, en virtud del permiso concedido). A su vez, la imprudencia inconsciente propia ya del tipo objetivo no alcanzará el hecho potencial doloso cuando el grado de riesgo del curso causal alternativo, extraído intersubjetivamente de las circunstancias, supere el nivel de relevancia del riesgo sin alcanzar el grado de probabilidad de lesión, y ello con total independencia de cualquier factor volitivo que pretenda incorporarse en sede de tipicidad subjetiva ${ }^{33}$.

\section{La realización del riesgo en el resultado en caso de comportamiento alternativo conforme a Derecho}

Además de en la imputación al dolo, la realización del riesgo en el resultado plantea dificultades en los casos de comportamiento alternativo conforme a Derecho.

En un reciente y completo trabajo ${ }^{34}$, Gimbernat Ordeig divide en tres grandes grupos los casos de comportamiento alternativo conforme a Derecho:

1. En un primer grupo de casos, si, debido a la concurrencia de una circunstancia especial, se llega a la conclusión de que el peligro de lesión era idéntico con o sin infracción de la norma de cuidado, entonces «la acción imprudente, paradójica y excepcionalmente, no ha sobrepasado el riesgo permitido, y, como no lo ha sobrepasado, debe considerarse también permitida» ${ }^{35}$.

2. En caso de duda razonable respecto de «si la acción incorrecta supuso un incremento del riesgo de lesión que encerraba ya el comportamiento alternativo conforme a Derecho, procede, en aplicación del principio in dubio pro reo, la absolución» ${ }^{36}$.

3. Como regla general, y en cualquier otro caso de infracción de la norma de cuidado, hay que afirmar la imputación objetiva

33 Recuérdese la apreciación de Roxin de que, sin norma de cuidado positiva, niveles de riesgo entre el $0,1 \%$ y el $1 \%$ se mueven «en una dimensión que habla decididamente en contra del dolo eventual», Roxin, $P G$, (tr. 2. $\left.{ }^{a}\right), 1997,12 / 72$, nota 136, pp. 452-453; AT I, 4. Auflage, 2006, 12/83, nota 169, p. 476.

${ }^{34}$ El comportamiento alternativo conforme a Derecho. De la causalidad a la imputación objetiva, B de F, Montevideo-Buenos Aires, 2017.

35 GIMBERNAT ORDEIG, El comportamiento alternativo conforme a Derecho, 2017, pp. 77-78.

36 GimbernAt ORDEIG, El comportamiento alternativo conforme a Derecho, 2017, p. 87. 
del resultado siempre y cuando conste que, en el caso concreto, la acción correcta no ejecutada representaba un riesgo menor (justamente, el permitido) de provocar el resultado lesivo efectivamente causado por la acción imprudente ${ }^{37}$. Esto es así porque «pertenece a la esencia del delito imprudente» que «la acción correcta no lo es porque no represente ningún riesgo para el bien jurídico protegido: lo es, porque ese riesgo es el jurídicamente tolerado y encierra una posibilidad de lesión de dicho bien jurídico menor (o mucho menor o incomparablemente menor) que aquella otra acción en la que se somete a dicho bien a un riesgo prohibido» ${ }^{38}$. De modo que, al sobrepasar impunemente el riesgo permitido - y en tanto que, "por definición, y porque encierra también un (aunque mucho menor) peligro de lesión, la acción correcta siempre puede causar el mismo resultado» ${ }^{39}$-, convertimos en papel mojado la norma de cuidado, olvidándonos de que una nueva ponderación realizada en ese nivel mayor de riesgo tal vez llevaría al legislador a una prohibición general de la conducta, ahora permitida en el actual nivel menor de riesgo ${ }^{40}$.

Esta contundente crítica a la teoría de la evitabilidad se acompaña de la aseveración de que la teoría del incremento del riesgo no opera «con ningún proceso causal hipotético», pues la absolución del autor imprudente causante de un resultado típico, con independencia de lo que hubiera podido pasar hipotéticamente con un comportamiento alternativo conforme a Derecho, depende de si «la acción correcta era o no menos peligrosa para el bien jurídico que la contraria al deber efectivamente ejecutada ${ }^{41}$.

La afirmación de que la teoría del incremento del riesgo no opera con ningún proceso causal hipotético es cierta —con la excepción que se verá más adelante- por dos razones:

a) Es cierta porque para la imputación objetiva en caso de infracción de la norma de cuidado se exige «la realidad incontestable de que el daño ha sido causado materialmente por una acción cuyo potencial lesivo era superior (o muy superior) al que el Derecho se había declarado dispuesto a tolerar ${ }^{42}$.

b) Pero dicha afirmación es también cierta en un nivel interpretativo más profundo.

\footnotetext{
37 GimBERnAT ORDEIG, El comportamiento alternativo conforme a Derecho, 2017, p. 81.

38 Gimbernat ORDEIG, El comportamiento alternativo conforme a Derecho, 2017, p. 49.

39 Gimbernat ORdeIG, El comportamiento alternativo conforme a Derecho, 2017, pp. 49-50.

40 GimBernat ORDEIG, El comportamiento alternativo conforme a Derecho, 2017, pp. 48-50.

41 Gimbernat ORDeIg, El comportamiento alternativo conforme a Derecho, 2017, p. 86.

42 Gimbernat ORDEIG, El comportamiento alternativo conforme a Derecho, 2017, p. 50.
} 
Como regla general, la tesis de Gimbernat Ordeig se basa en la idea de que en la práctica totalidad de supuestos en que se produce la lesión de un bien jurídico a consecuencia de una acción imprudente hay un incremento del riesgo permitido que provoca la imputación objetiva del resultado ${ }^{43}$.

No obstante, hay que entender que lo anterior no impide que, dado en la realidad otro curso causal concurrente, pueda negarse la imputación objetiva del resultado por ausencia de realización del riesgo en el resultado. Así, por ejemplo, si, quien ha recibido una inyección mortal por vulneración imprudente de la lex artis médica, fallece por una posterior imprudencia médica grave de tercero, es posible, dado el caso, negar la imputación objetiva del resultado a la primera acción pese a un incontestable incremento del riesgo derivado de esa primera acción imprudente ${ }^{44}$.

Gimbernat Ordeig no aborda este problema por la sencilla razón de que su trabajo estudia el comportamiento alternativo conforme a Derecho, y la imprudencia de tercero del ejemplo anterior no es un comportamiento conforme a Derecho, pero tampoco es un comportamiento alternativo, pues, en nuestro ejemplo, ha sucedido realmente. Por lo tanto, fuera de los casos excepcionales, basta el incremento del riesgo — dada una infracción de la norma de cuidado- para afirmar la imputación objetiva del resultado ${ }^{45}$.

43 Véase Gimbernat ORdeig, El comportamiento alternativo conforme a Derecho, 2017, pp. 82-83.

${ }^{44}$ Así, «cuando unas heridas imprudentes potencialmente letales conduzcan a la muerte en un proceso causal irregular, la imputación o no imputación de aquélla al autor originario se determinará acudiendo al siguiente procedimiento: si la muerte se ha producido en el caso concreto por una imprudencia médica que también habría conducido al mismo resultado en heridas de carácter menos grave o leve, entonces el resultado final no se le debe imputar al autor imprudente de las heridas potencialmente letales», Cursos causales irregulares e imputación objetiva, Gimbernat Ordeig, B de F, Montevideo-Buenos Aires, 2011, p. 107.

${ }_{45}$ MARTínez Escamilla rechaza la influencia del comportamiento alternativo conforme a Derecho en el juicio de imputación objetiva, pero también rebate la tesis del incremento del riesgo, pues «lo que hubiera sucedido en el caso concreto de haberse comportado el autor diligentemente es totalmente irrelevante a efectos de la constatación del nexo de riesgo. La necesidad de éste no conlleva inexorablemente la relevancia del comportamiento hipotético. Ambas cuestiones son independientes, siendo lo determinante para la imputación objetiva del resultado la constatación del nexo en cuya definición no es decisivo ni el principio de evitabilidad ni el del incremento del riesgo. De esta manera, podrá afirmarse que el resultado es la realización de la lesión del deber de diligencia a pesar de que en el caso concreto el comportamiento correcto no habría evitado la lesión o habría generado un riesgo igual al que el comportamiento imprudente creó. Lo contrario también es posible: puede excluirse la imputación objetiva a pesar de la constatación de la evitabilidad o del aumento del riesgo. Lo decisivo será si el resultado es de aquellos cuya producción la norma de cuidado infringida tenía por misión evitar o reducir», La imputación objetiva del resultado, Publicaciones del Instituto de Criminología de la Universidad Complutense, tomo 60, Madrid, 1992, p. 236. Véase, también, MARTíNEZ EsCAMILLA, "¿Relevancia de los comportamientos alternativos conformes a Derecho en la imputación objetiva del resultado?», Omisión e imputación objetiva en Derecho penal. Jornadas hispano-alemanas de Derecho Penal en homenaje al profesor Claus Roxin, Gimbernat, Schünemann, Wolter, (Edits.), Centro de Estudios Judiciales, Servicio de Publicaciones de la Facultad de Derecho de la Universidad Complutense, Madrid, 1994, pp. 105 y ss. 
Pero el problema que aquí se plantea es el de si la imputación objetiva del resultado requiere, en caso de conducta alternativa conforme a Derecho, de la atención a un curso causal hipotético para la afirmación de la realización del riesgo en el resultado; exigencia que, en términos de la teoría de la evitabilidad ${ }^{46}$, se puede plantear así: no hay imputación cuando la conducta correcta hubiera llevado con alguna probabilidad, según el cálculo humano, o con una posibilidad más o menos alta, al mismo resultado ${ }^{47}$.

Para responder a la cuestión anterior hay que considerar que un curso causal no dado en la realidad no puede desplazar al creado por el autor. Esto se puede formular del siguiente modo: en los casos de comportamiento alternativo conforme a Derecho, el incremento del riesgo permitido se corresponde con la imputación objetiva del resultado, pues solo ese riesgo puede realizarse en el resultado, en tanto que cualquier otro riesgo hipotético carece, por definición, de eficacia en el mundo real.

La impugnación que hace Gimbernat Ordeig de los cursos causales hipotéticos implica un rechazo, en mi opinión, correcto, de los juicios hipotéticos respecto de la realización del riesgo en el resultado: afirmado el incremento del riesgo, sin otro curso causal concurrente hay que afirmar sin más - y a salvo el fin de protección de la norma de cuidado infringida ${ }^{48}$ - la realización del riesgo en el resultado.

Ahora bien, para afirmar o negar el incremento del riesgo hay que acudir a un curso causal hipotético, pues solo se puede saber si la acción correcta y la incorrecta encerraban o no el mismo riesgo de lesión si imaginamos qué hubiera ocurrido si la acción hubiese sido la correcta (algo que no ocurrió). Es necesario servirse de un curso causal hipotético, es decir, de un curso causal no dado en la realidad: el ajustado a la norma de cuidado.

Si la teoría del incremento del riesgo se limitase a decir que toda infracción de la norma de cuidado implica un incremento del riesgo, entonces no habría curso causal hipotético alguno. Pero si atiende a cada caso en particular, entonces la atención al proceso causal hipotético es

46 Véase, para las diferentes manifestaciones de la teoría de la evitabilidad, Gimbernat Ordeig, El comportamiento alternativo conforme a Derecho, 2017, pp. 14-27.

47 Así, FRISCH: «Mientras el castigo esté vinculado a la existencia de un resultado lesivo como resultado injusto, decae la posibilidad de un castigo cuando no es posible identificar el resultado acaecido como injusto. Y esto es lo que sucede cuando no solo es teóricamente imaginable, sino que desde una óptica realista se muestra como posible que el resultado se hubiera producido igualmente en caso de darse un comportamiento conforme a Derecho, esto es, cuando resulta posible que el resultado no sea la consecuencia específica del preciso comportamiento contrario a Derecho", La imputación objetiva del resultado. Desarrollo, fundamentos y cuestiones abiertas, Atelier, Barcelona, 2015, p. 99; traducción de Ivó Coca VILA.

48 Véase la nota 52. 
obligatoria, pues hay un único curso causal real, y para saber si ese curso causal real ha incrementado el riesgo de lesión hay que compararlo con un curso causal no acontecido, hipotético, y acorde con la norma de cuidado.

Esta acción correcta, imaginada, puede provocar que la acción imprudente, excepcionalmente, no sobrepase el riesgo permitido y se considere, en consecuencia, permitida ${ }^{49}$.

Para saber por qué hay que valorar un curso causal hipotético respecto del incremento del riesgo y no respecto de la realización del riesgo en el resultado debemos acudir a criterios político-criminales. Hay que excluir la imputación objetiva en caso de conducta alternativa conforme a Derecho igualmente lesiva porque no se puede castigar por la infracción de un deber "cuyo cumplimiento hubiera sido inútil» ${ }^{50}$. Hay que mantener la imputación objetiva en caso de incremento del riesgo porque si se excluyera la imputación en caso de que la conducta acorde con el riesgo permitido "hubiera podido causar el mismo resultado», entonces "sería el autor imprudente quien, al margen del Derecho, fijaría su propio riesgo permitido, derogando ese riesgo permitido establecido por la lex artis o por las medidas de prevención de riesgos que se establecen en las normas extrapenales que regulan el ejercicio de actividades peligrosas ${ }^{51}$.

En consecuencia con lo anterior, el problema de la posible vulneración del principio in dubio pro reo queda circunscrito al incremento del riesgo. Si no se atiende a cursos causales alternativos para la realización del riesgo en el resultado, no caben dudas al respecto: dado el incremento del riesgo, no hay nada más que probar ${ }^{52}$. Pero respecto del incremento del riesgo, es decir, respecto del único juicio que implica una atención al hipotético curso causal que hubiera desencadenado un comportamiento alternativo conforme a Derecho, sí hay que atender al principio in dubio pro reo, como revela la solución dada por Gimbernat Ordeig a los casos inciertos ${ }^{53}$.

49 GimBernat ORDEIG, El comportamiento alternativo conforme a Derecho, 2017, pp. 77-78.

50 Roxin, $P G$, (tr. 2. ${ }^{a}$ ), 1997, 11/64, p. 376; AT I, 4. Auflage, 2006, 11/74, p. 387.

51 GIMBERNAT ORDEIG, El comportamiento alternativo conforme a Derecho, 2017, p. 49.

52 Una posterior y posible duda respecto de la inclusión del resultado dentro del fin de protección de la norma de cuidado infringida no puede acogerse al principio in dubio pro reo ni quedar sin resolver en el proceso, pues no se trata de un problema fáctico, como el de si se ha dado o no en la realidad un incremento del riesgo permitido, sino de un problema interpretativo: el de si, de acuerdo con una interpretación teleológica, los hechos conocidos pueden ser subsumidos en la correspondiente norma penal, por ejemplo, el art. 142 CP. Para la relación entre incremento del riesgo y fin de protección de la norma en caso de comportamiento alternativo conforme a Derecho, véase GIMBERNAT ORDEIG, «El delito de omisión impropia», Estudios sobre el delito de omisión, B de F, MontevideoBuenos Aires, 2013, p. 283, nota 48; también, GIMBERNAT ORDEIG, El comportamiento alternativo conforme a Derecho, 2017, pp. 89-99.

${ }_{53}$ Gimbernat ORdeIG, El comportamiento alternativo conforme a Derecho, 2017, pp. 83-86. 


\section{Conclusiones}

1. Si el grado de riesgo es un objeto del dolo, entonces es que forma parte del tipo objetivo, y ello no solo para la imputación objetiva, sino también para la distinción entre dolo eventual e imprudencia consciente.

2. La realización del riesgo en el resultado deja abierto un campo de juego para la imputación al dolo en las desviaciones del curso causal: la diferencia entre ambas es la diferencia entre infracción del deber de cuidado y co-consciencia, conceptos cercanos en caso de dolo normativo pero no equivalentes.

3. La teoría del incremento del riesgo opera con procesos hipotéticos para la creación de un riesgo relevante pero no para la realización del riesgo en el resultado. Con ello se satisfacen dos exigencias político-criminales: que el incumplimiento de una norma inútil no sea punible y que los límites del riesgo permitido no sean fijados al arbitrio del autor. 